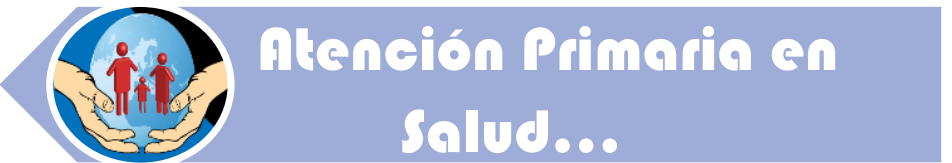

\title{
ANÁLISIS de LA POLITICA INTEGRAL EN SALUd
}

Guillermo Restrepo $\mathrm{Ch}^{* * *}$. Juan Carlos González Q. ${ }^{++}$

\section{POLÍTICA DE ATENCIÓN INTEGRAL EN SALUD}
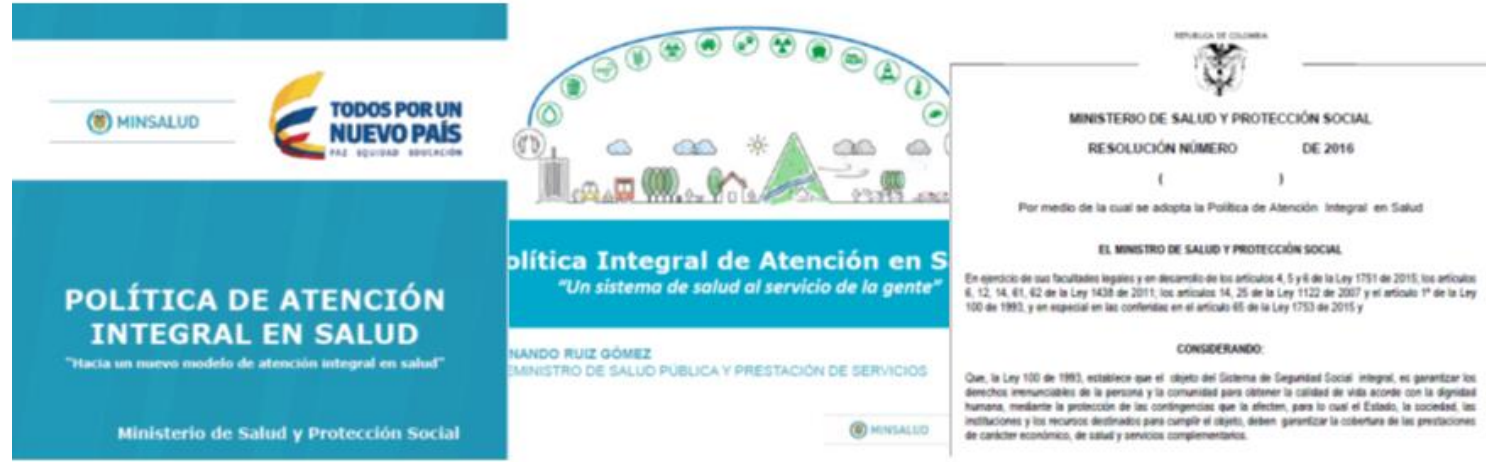

OBJETIVO: Máxima salud, acceso, intersectorialidad, circunstancias

\footnotetext{
Por considerarlo un deber para con nuestros lectores y un deber de divulgación con el país, a continuación vamos a exponer un resumen del documento "Política de Atención Integral en Salud" (incluyendo algunos comentarios personales entre paréntesis y al final un breve análisis). Como siempre, las opiniones que acá se exponen, en ningún momento reflejan la postura de la Fundación Universitaria Juan N Corpas. Son tan solo expresiones de las posturas de los que firman el artículo.

En la página del Ministerio de Salud https://www.minsalud.gov.co/Paginas/politica-integral-de-atencionen-salud.aspx puede encontrar los tres documentos bases de este resumen. Le recomendamos leerlos. En tanto lo hace, esperamos que este resumen lo motive.
}

\section{El objetivo}

Esta política busca responder a los problemas de salud actuales y cumplir con el mandato de desarrollar un modelo de salud enfocado bajo la estrategia de la Atención Primaria en Salud (APS).

*** MD MPS. Director Postgrado Gerencia en Salud. FUJNC - guillermo.restrepo@juanncorpas.edu.co

${ }^{++\dagger}$ MD MPS. Director Departamento de Medicina Comunitaria. FUJNC - juan.gonzalez@juanncorpas.edu.co

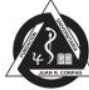

Carta Comunitaria. Vol. 24. Número 137. Marzo - Abril 2016 


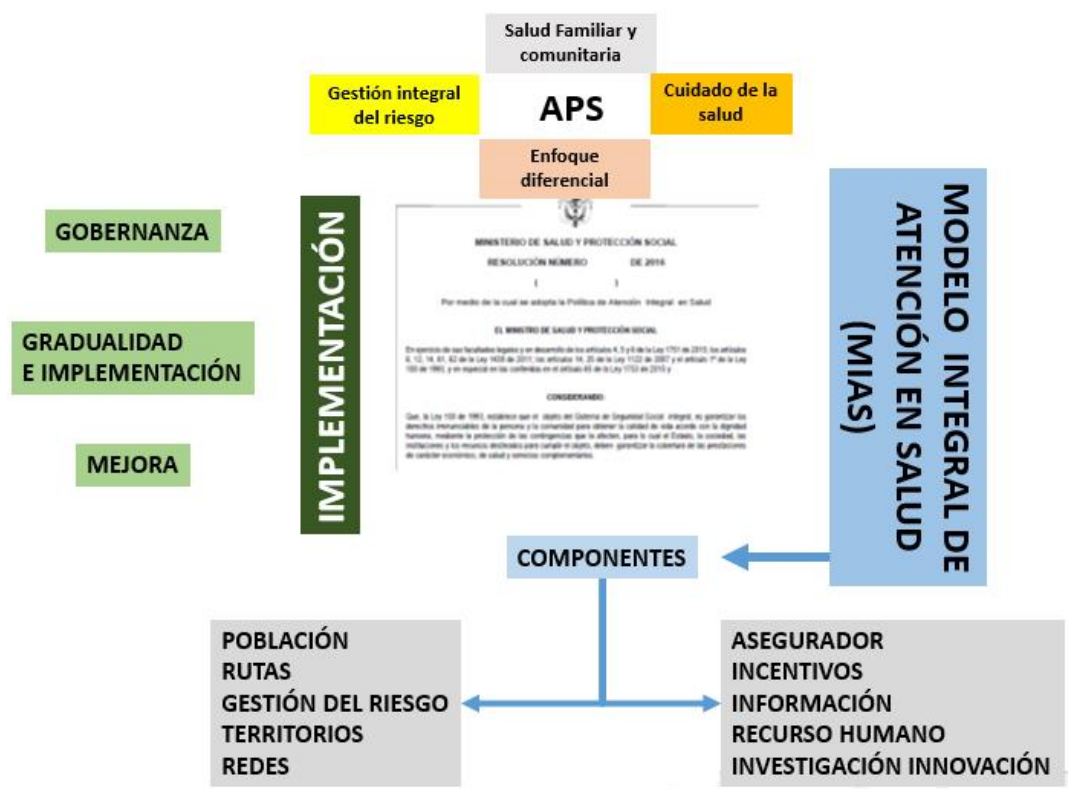

Propone la resolución impulsar la implementación de un modelo de atención integral, basado en la APS, donde se haga énfasis en la salud familiar y comunitaria, el cuidado de la salud, la gestión del riesgo y el enfoque diferencial en la población. La resolución expone los componentes que deberá tener el modelo y propone que la implementación sea paulatina y que se vaya corrigiendo.

\section{La política}

El documento está organizado en tres partes. Una primera en donde plantean los logros y los problemas existentes del actual sistema de seguridad social.

Una segunda parte donde plantean los cambios que implica la ley estatutaria en torno a la salud.

La tercera, y última parte, está destinada a explicar la política de atención integral y allí mismo se exponen las bases del modelo integral de atención en salud.

\section{Logros}

\section{EVALUACIÓN}

OBJETIVOS CENTRALES: EXPANDIR PROTECCIÓN FINANCIERA
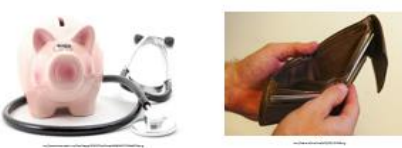

GASTO DE BOLSIUO
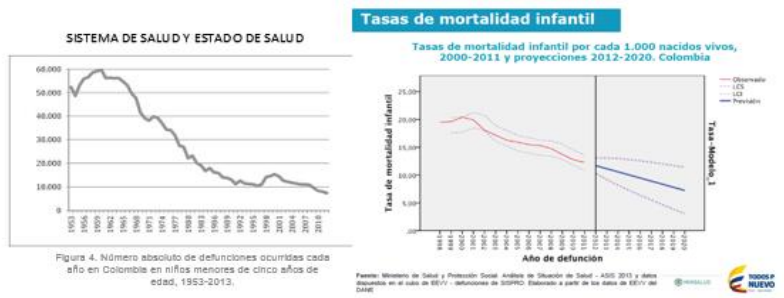

OBJETIVOS CENTRALES: MEJORAR EL ACCESO

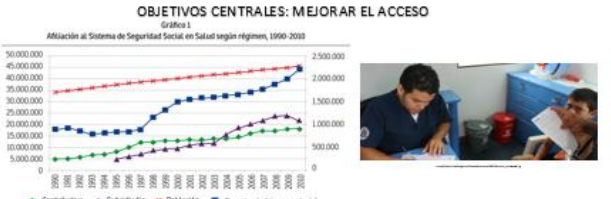

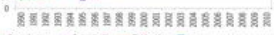

COBERTURA DE SEGURIDAD SOCIAL

Mortalidad en descenso

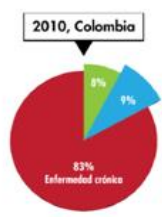

Carta Comunitaria. Vol. 24. Número 137. Marzo - Abril 2016 
Siendo la seguridad social un sistema de aseguramiento y de protección, el documento considera que ciertamente ha brindado protección en las catástrofes derivadas de la pérdida de la salud, que resulta particularmente evidente en la franca disminución del gasto de bolsillo de los colombianos.

Un segundo elemento de logro ha sido la cobertura de la población dentro del sistema. Si bien aún el acceso real es cuestionable, no existe duda de que el hecho de estar afiliado le permite a la población hacer cumplir, e incluso exigir, el acceso real.

El descenso de la mortalidad general (aumento de la esperanza de vida), la disminución de la mortalidad infantil y ese patrón de dominio en la morbilidad de las enfermedades crónicas, son interpretados por los autores del documento como logros.

\section{Las debilidades}

\section{EVALUACIÓN...}
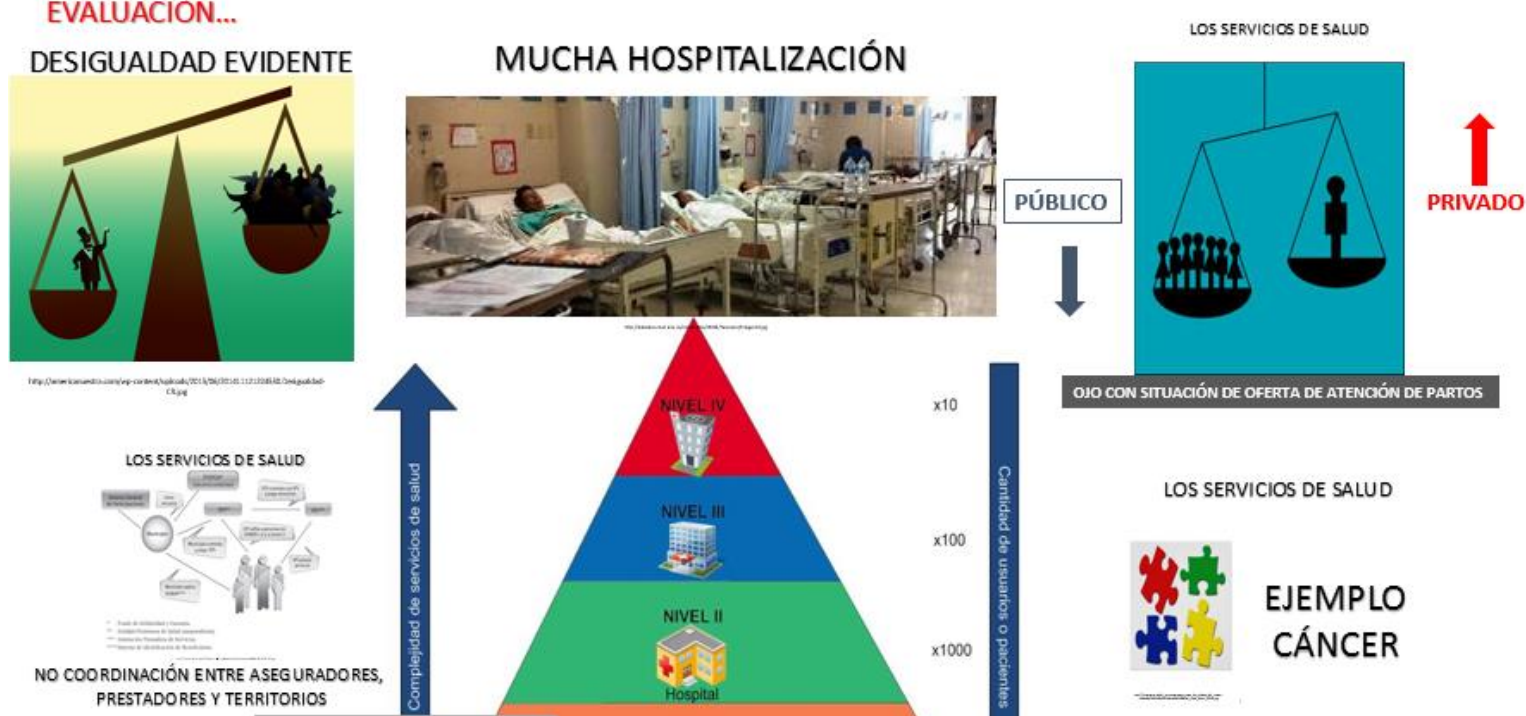

INCAPAZ

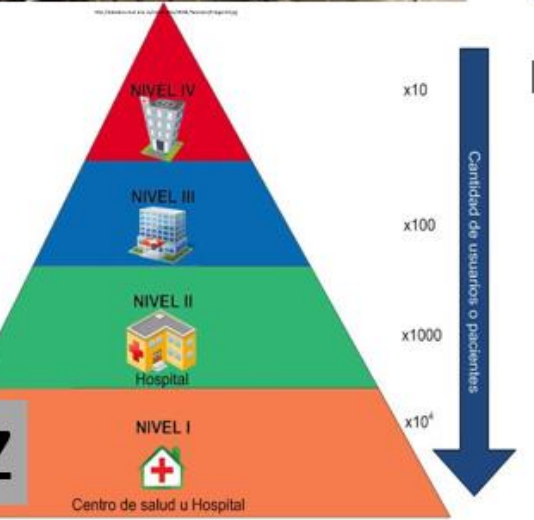

LOS SERVICIOS DE SALUD

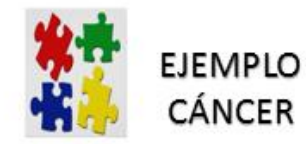

FRACCIONAMIENTO VS INTEGRALIDAD

Plantea que las debilidades son muchas... Expone cómo la desigualdad entre unos muy pocos (ricos) y la mayoría, que son pobres, es muchísima.

Expone cómo el modelo actual promueve la hospitalización. Cómo lo público está desapareciendo mientras lo privado va creciendo (en concreto en torno a las IPS).

Afirma cómo la coordinación se ha vuelto muy compleja pues se ha desarrollado muchísima intermediación.

Expone cómo con el ejemplo de la atención del cáncer, se demuestra una fragmentación lamentable de la atención. En un sitio lo diagnostican, en otro dan la quimioterapia, en otro lo operan, en otro hacen la radioterapia, etc...

Y lo más lamentable... la incapacidad del nivel primario para resolver, para atender, en fin, para cumplir con ese deber de ser el mejor sitio de contacto entre los servicios y las personas. 


\section{Lamentable... las relaciones humanas}

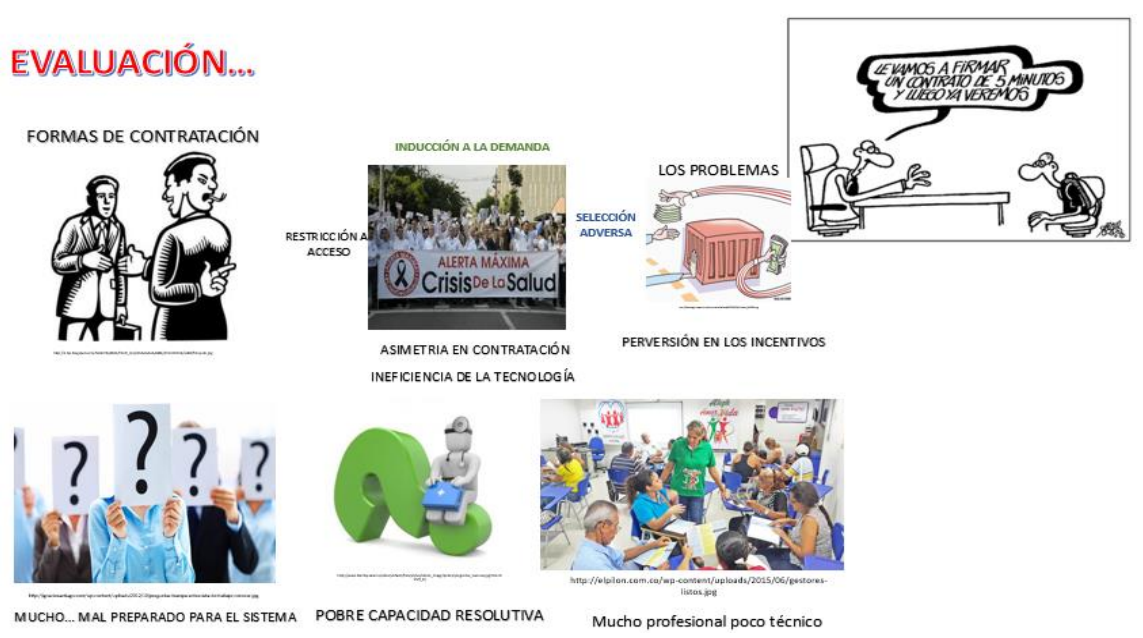

El documento critica particularmente el desarrollo humano derivado. Existen contratos laborales perversos, se promueven relaciones no éticas entre las partes ("el que tiene plata marranea"), un desprecio por el trabajo comunitario y el ejercicio de profesionales poco comprometidos.

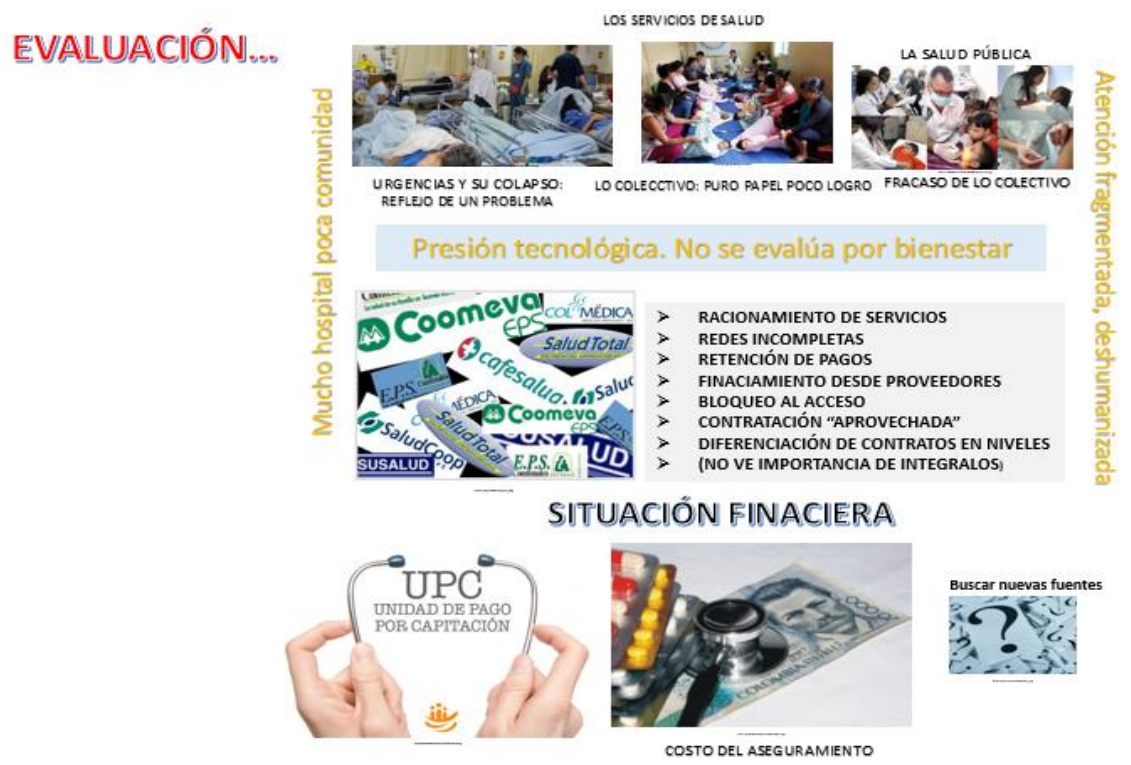

Pone de manifiesto el colapso de los servicios de urgencias, el fracaso de las políticas públicas, la disminución de las actividades colectivas (mucho papel firmado y poca promoción ofrecida), así como también censura a las EPS por aquello en lo que se han convertido: obstructoras de la prestación a través de la congestión de las autorizaciones, retenedoras perversas de pagos (cuando saben que pueden ganar intereses manteniendo los recursos por un tiempo), se apalancan en los proveedores (qué tal: los pobres financiando a los ricos) y generando contratos asimétricos con las IPS (aplicando la ley del embudo: lo ancho para ellas y lo angosto para la IPS).

Plantea también el debate existente de, si con los recursos financieros, se puede dar el plan de beneficios. 


\section{La posición del Ministerio}

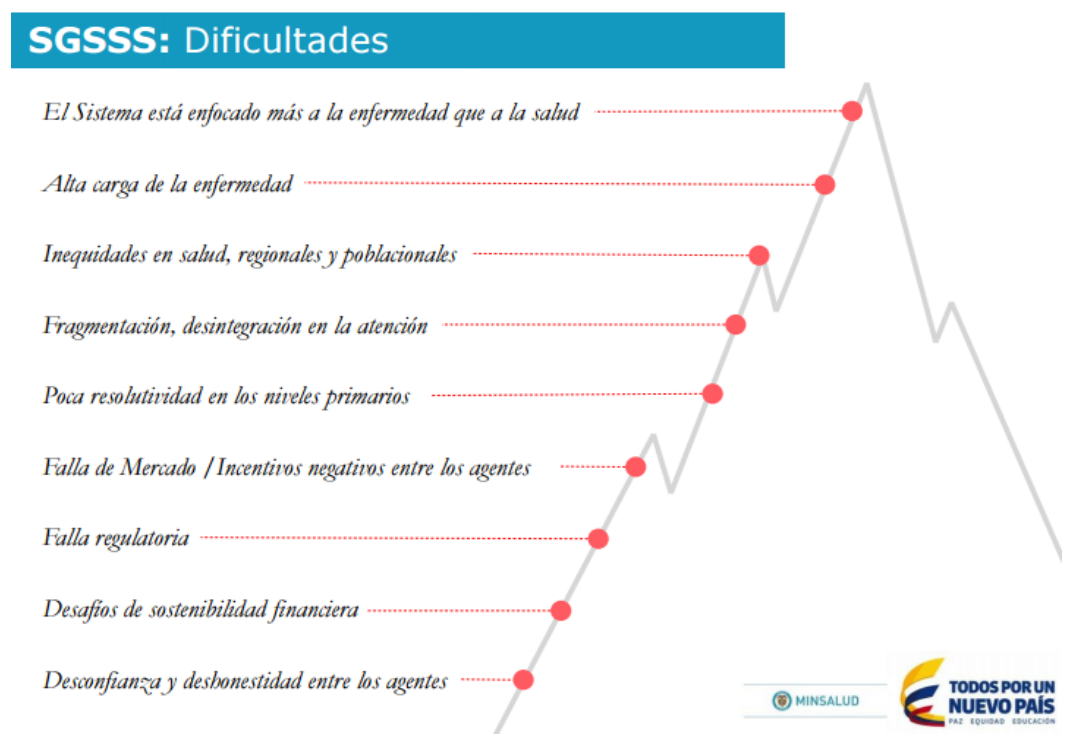

El viceministro Fernando Ruiz en una presentación expone con la gráfica anterior las debilidades del sistema actual.

\section{La ley estatutaria}

Sistema de salud, ley estatutaria y plan de desarrollo
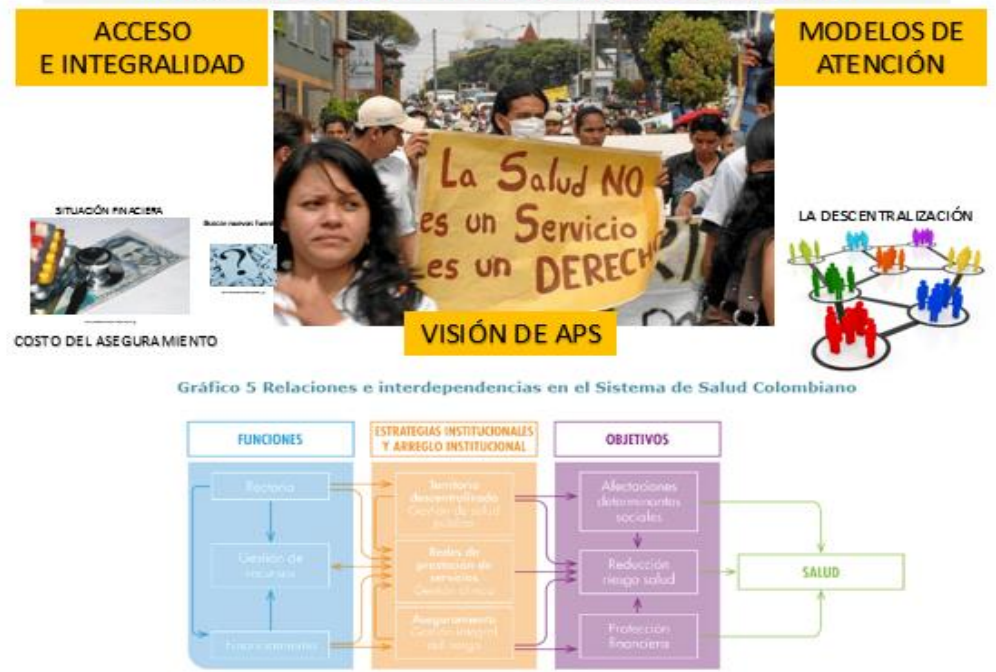

Fuente: Adaptación de los actores al marco conceptual del WHO World Health Report 2000

Expone la política de cómo la ley estatutaria, que busca hacer real el derecho a la salud de la persona, está basada en la APS, promoviendo el acceso y la integralidad en el manejo y considera la necesidad de construir modelos reales donde esto se ve realmente aplicado. En tal sentido, enfatiza la rectoría que debe existir en torno a la forma como la población recibe los servicios de salud, dejando al Estado como directo responsable. Además, pone los recursos financieros y la rectoría al servicio de la gestión 
de los recursos, planteando que los territorios velen por la gestión pública, las redes de servicios por la gestión clínica y el aseguramiento por la gestión del riesgo. Proponiendo que de esta manera se intervenga sobre los factores determinantes y los riesgos y se proteja lo financiero, con lo cual el resultado será la salud de la persona, de su familia y de la población.

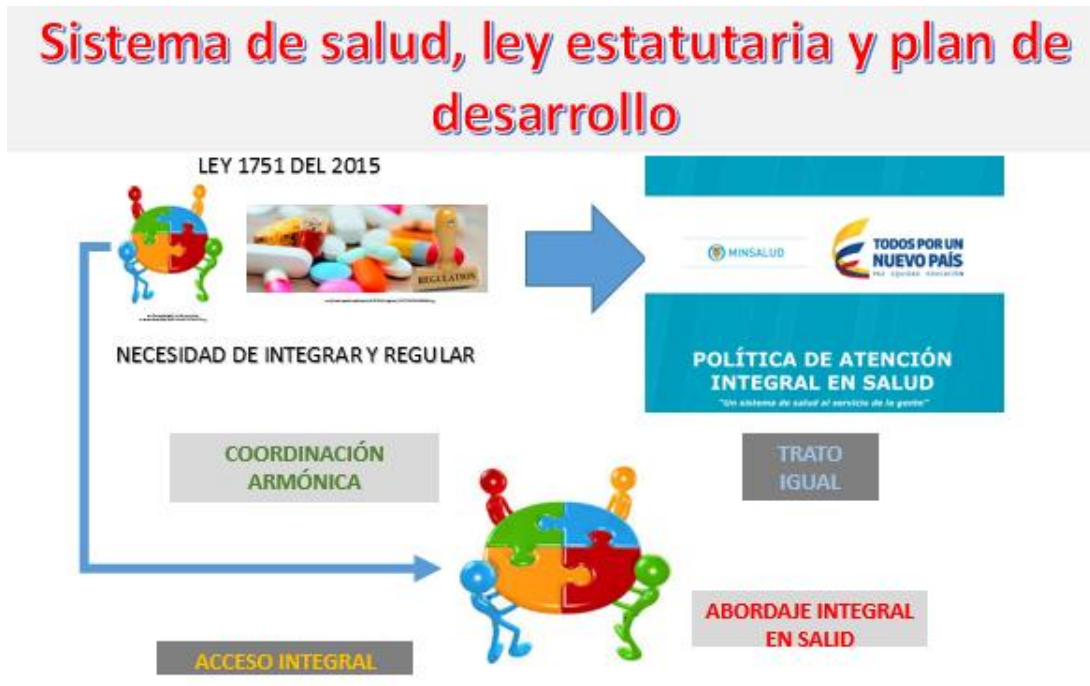

INTEGRALIDAD

Afirma que la ley estatutaria ordena la búsqueda de la integralidad para darle el máximo de salud a la población, y para ello promueve la integralidad a través de la coordinación armónica que ha de existir entre los diversos componentes del sistema, el trato igualitario, el acceso integral y el abordaje completo. Por ende, a ello ha de responder esta política y el modelo.

\section{La política propiamente dicha}

\section{POLÍTICA DE ATENCIÓN INTEGRAL DE SALUD}

\section{Sistema de salud vs Seguridad social}

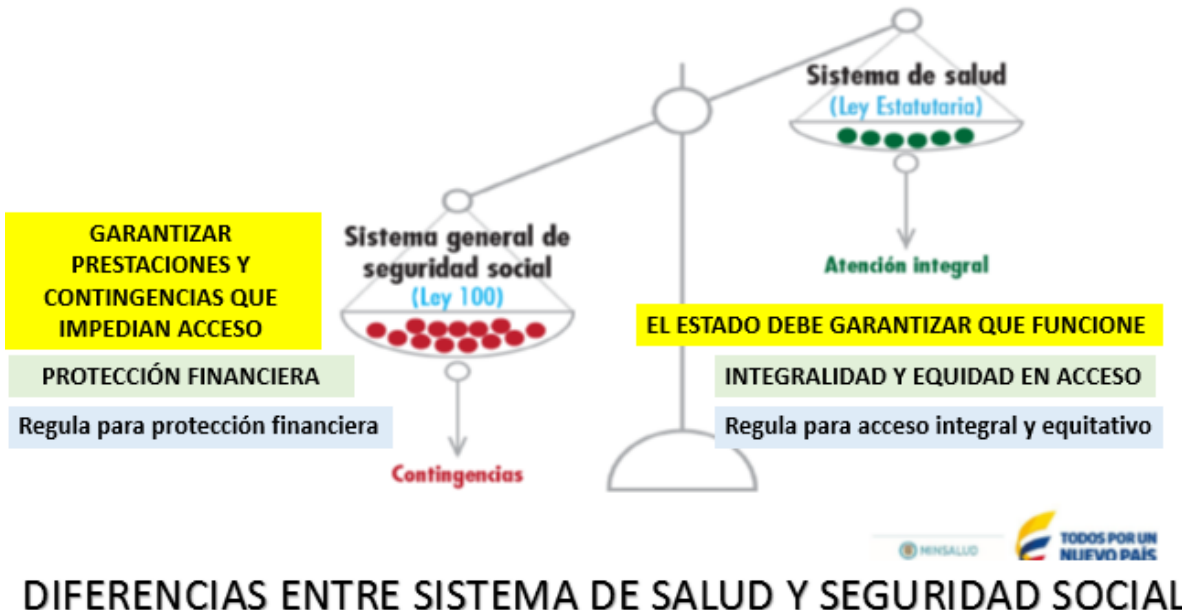

Carta Comunitaria. Vol. 24. Número 137. Marzo - Abril 2016 
Se plantea la diferencia entre lo que ha sido el sistema de seguridad social y el nuevo sistema que promueve la ley estatutaria de esta forma:

1. En la seguridad social lo fundamental es garantizar las prestaciones cuando se necesitan, en el sistema de salud la integralidad, el acceso a los servicios y la equidad.

2. La protección financiera de los afiliados era clave en la seguridad social. El bienestar y la preservación del bienestar en la persona es la clave del nuevo sistema de salud.

3. En el sistema de seguridad social, el Estado actúa como regulador entre los distintos componentes. En el nuevo sistema el Estado es el responsable.

\section{Cómo se concibe el Sistema de salud}

\section{Gráfico 6 Politica Integral de Atención en Salud, PAIS}

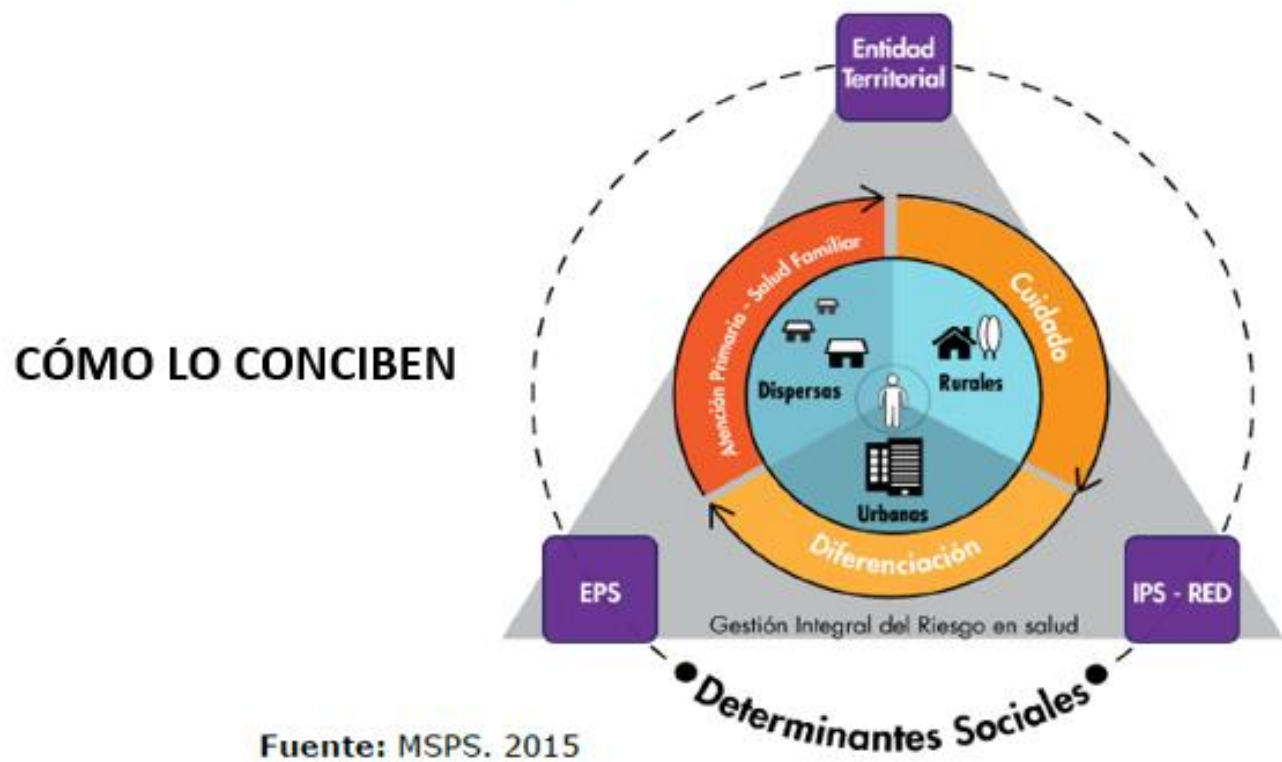

Poniendo al individuo en el centro (como razón nuclear de ser) y teniendo en cuenta el territorio donde habita (urbano, rural y dispersos) ha de recibir una atención donde:

- Se le ofrezca la estrategia de la APS/Salud Familiar.

- Se promueva el cuidado preventivo.

- Se puedan hacer enfoques diferenciales en torno a las poblaciones.

Y ese modelo ha de ser coordinado por el ente territorial que asume unas responsabilidades, por las EPS que asumen otras y, por las redes integrales de salud que serán las encargadas de prestar la atención. Entre estas tres debe presentarse una coordinación que garantice el modelo. 


\section{Lo que debe tener el modelo}

\section{POLÍTICA DE ATENCIÓN INTEGRAL EN SALUD}
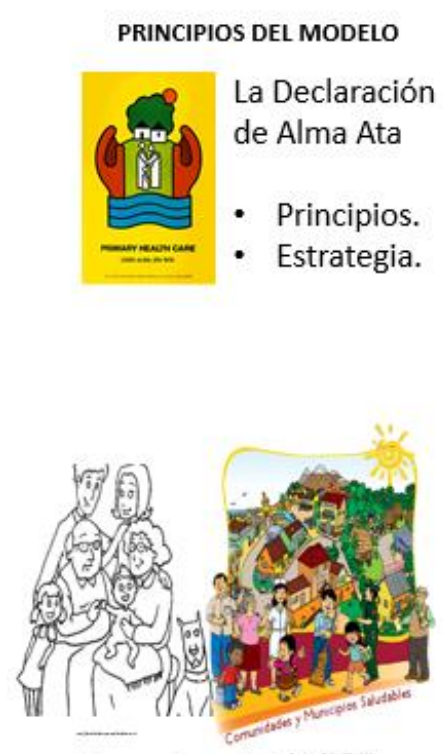

Enfoque de salud Familiar y comunitario
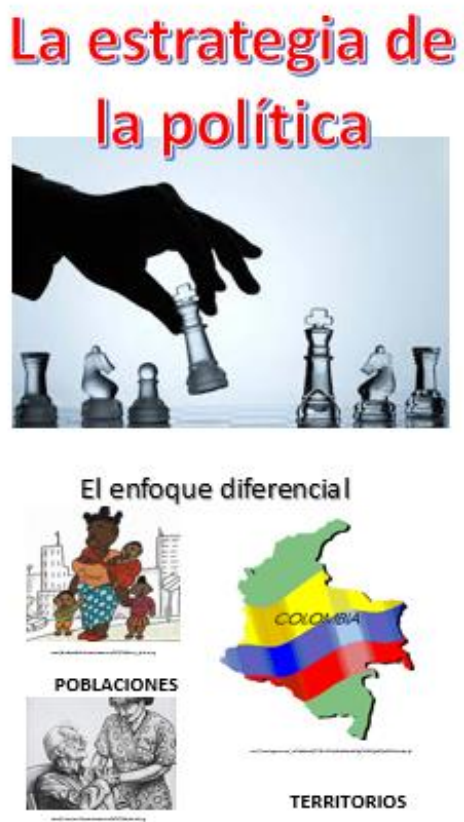

El cuidado de la salud
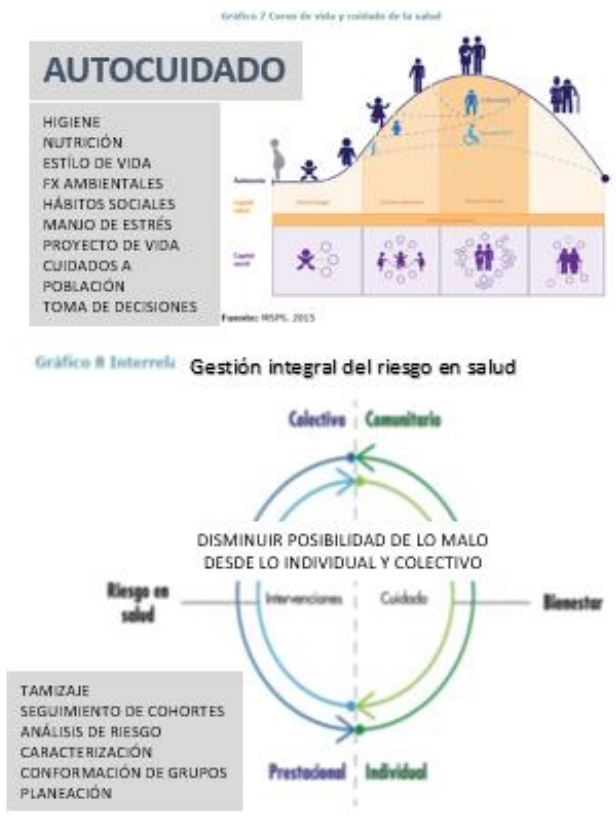

Fuenten sess. 2015.

Es importante que para implementar el modelo se debe cumplir con:

1. La estrategia de la APS basada en la Declaración de Alma Ata.

2. Los equipos primarios deben basarse en la atención cumpliendo con el enfoque que contempla no solo al individuo sino a su familia y a la comunidad donde habita (enfoque integral).

3. Debe promover que la persona, su familia y la comunidad adopten y asuman la responsabilidad de cuidarse, contemplando para ello el ciclo vital.

4. Debe caracterizarse a la persona y a la población e identificar e intervenir sobre los riesgos existentes.

5. Deben identificarse esas particularidades en torno a poblaciones vulnerables y vulneradas y que el modelo les responda con base en sus circunstancias. 


\section{El Modelo}

POLÍTICA DE ATENCIÓN INTEGRAL DE SALUD

\section{Modelo Integral de Atención en Salud}

\section{LO QUE DEBE TENER}

\section{LO QUE QUEREMOS}

Modelo integral de atención en salud
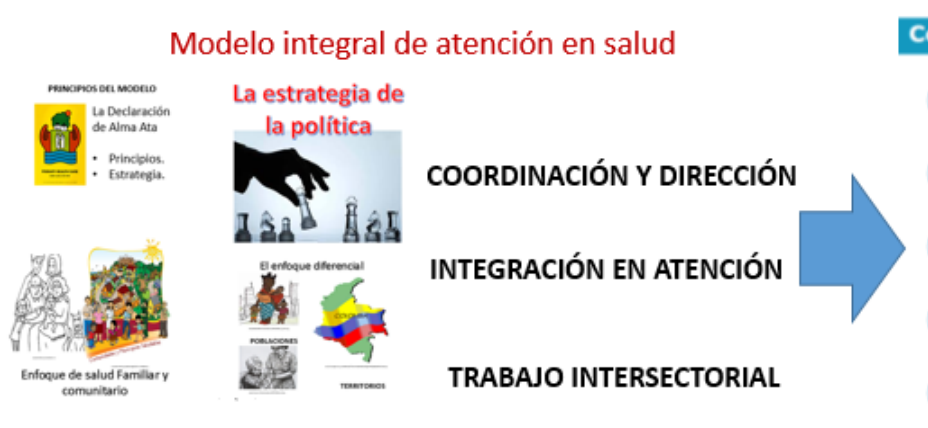

Tener todo lo necesario para no fragmentar

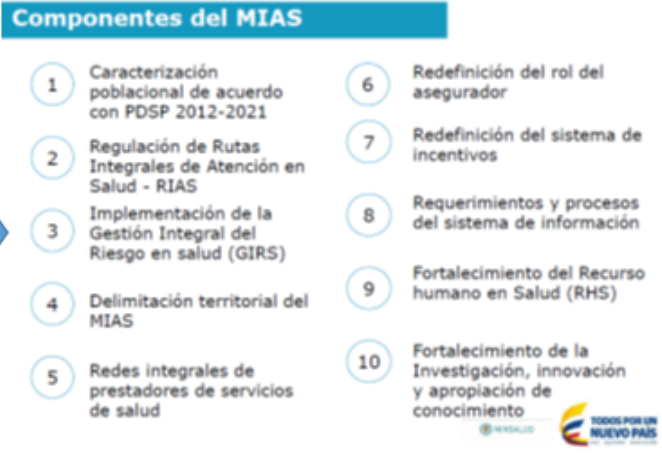

El documento propone los pasos que se deben dar para construir el modelo. Vale la pena insistir en lo que debe tener, agregando que al construirlo se debe dejar muy bien explicado cómo será la coordinación, la integración y cómo será la propuesta del trabajo intersectorial.

La caracterización de la persona y la población
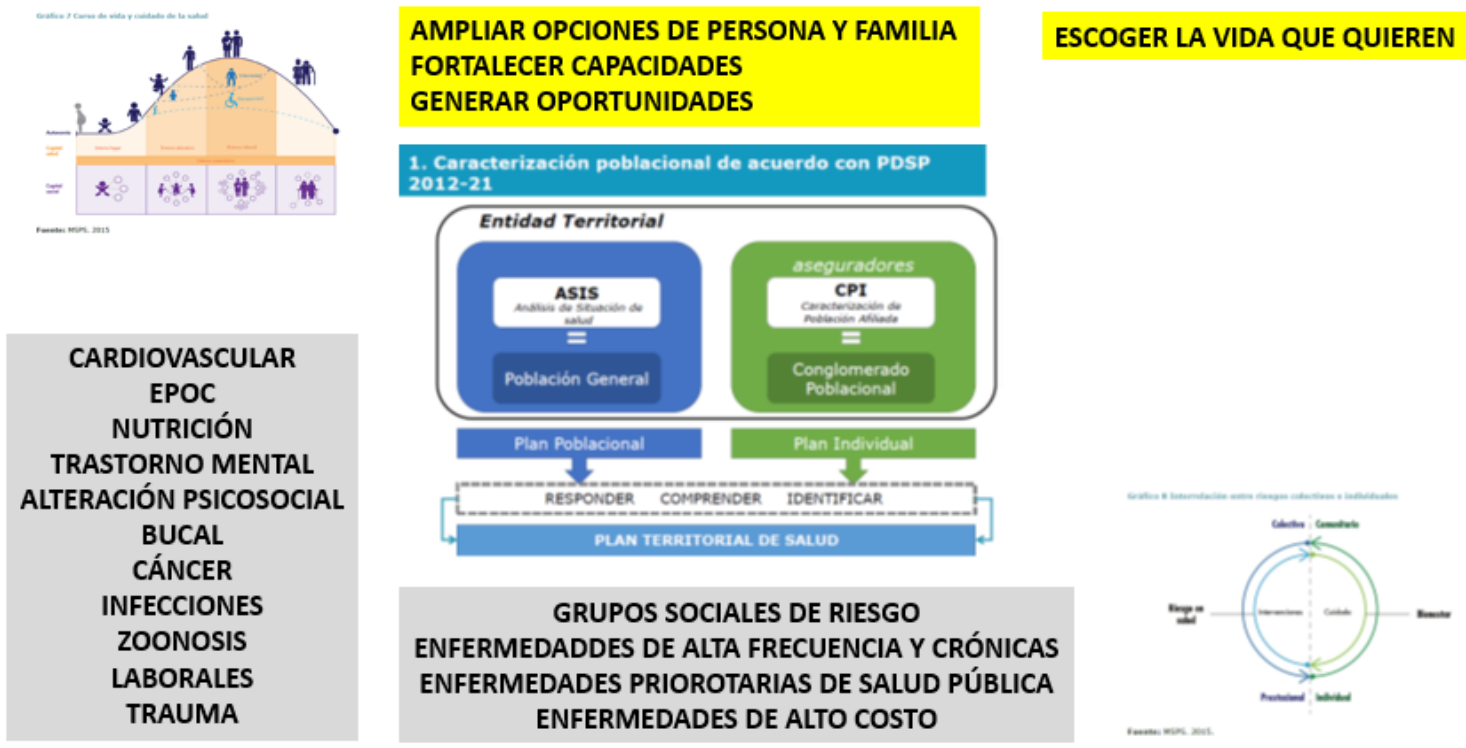

Ordena que la caracterización de la población la debe hacer el ente territorial a través de los ASIS y la individual la haga la EPS. La idea es que con dicho diagnóstico se hagan los planes de salud tanto del individuo y su familia como de la comunidad y con base en esto se ofrezca la atención, entendida 
no solo para cuando están enfermos, sino contemplada como la posibilidad de ofrecerle a la persona la capacidad de ser orientada para escoger la mejor vida posible. Por supuesto que de esta caracterización surgirá la detención de los riesgos y con ello la posibilidad de intervenir sobre ellos.

La clave: las rutas

\section{Rutas integrales: objetivo...j Vencer la fragmentación! \\ GUÍAS \\ Plan de intervenciones colectivas \\ TOMA DE DECISIONES \\ Plan de beneficios}
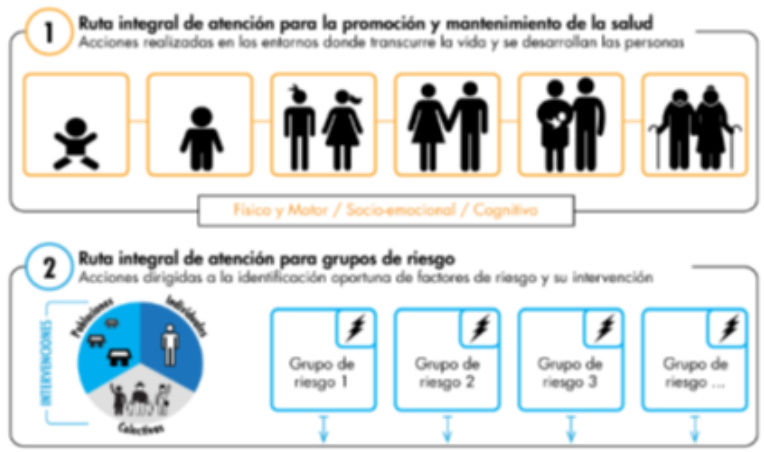

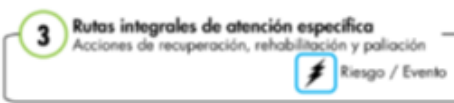

\section{Regulación de Rutas Integrales de Atención en Salud-} Eventos especificos

(1) Es el flujo regulado del usuario a lo largo del continuo de la atención integral

\{2\} Adaptada a las particularidades de un territorio y población

\{3\} Especifica hechos o acontecimientos clave del ciclo de la atención (hitos)

(4) Determina intervenciones colectivas e individuales (promoción, prevención primaria, secundaria y terciaria)

(5) Define estrategias y acciones, a desarrollar por la comunidad y las instituciones de salud y de otros sectores

\{6\} Incorpora normas técnicas, administrativas, protocolos y guias de práctica clinica

\section{Responsables de la integralidad}

Es la propuesta de cómo asegurar la integralidad, ya que estas rutas son las responsables de ofrecer la atención y de interconectar a los distintos actores.

Las rutas deben describir exactamente qué hacer ante las situaciones de las personas, sus familias y la comunidad y deben asegurar la atención de las necesidades de la mejor forma posible.

Concibe que las rutas han de estar basadas en ofrecer la atención basada en la mejor evidencia existente (componente racional) y con base en ello se tomarán en últimas las decisiones sobre la persona. Además debe asegurar que las intervenciones colectivas respondan a las necesidades de la población, ciertamente usando la mejor evidencia.

Establece tres rutas:

1. Una ruta para mantener la salud.

2. Una para los grupos de riesgos encontrados.

3. Una para la atención específica.

La ruta pone de manifiesto lo que debe hacer cada componente de la red, el papel de la aseguradora y el ente territorial. Por así decirlo, las rutas son los vasos sanguíneos que conectan el sistema para hacer real las intervenciones. Son las responsables de hacer efectiva desde la gestión de salud pública, la promoción de la salud, las acciones en los entornos, así como las actividades individuales. 


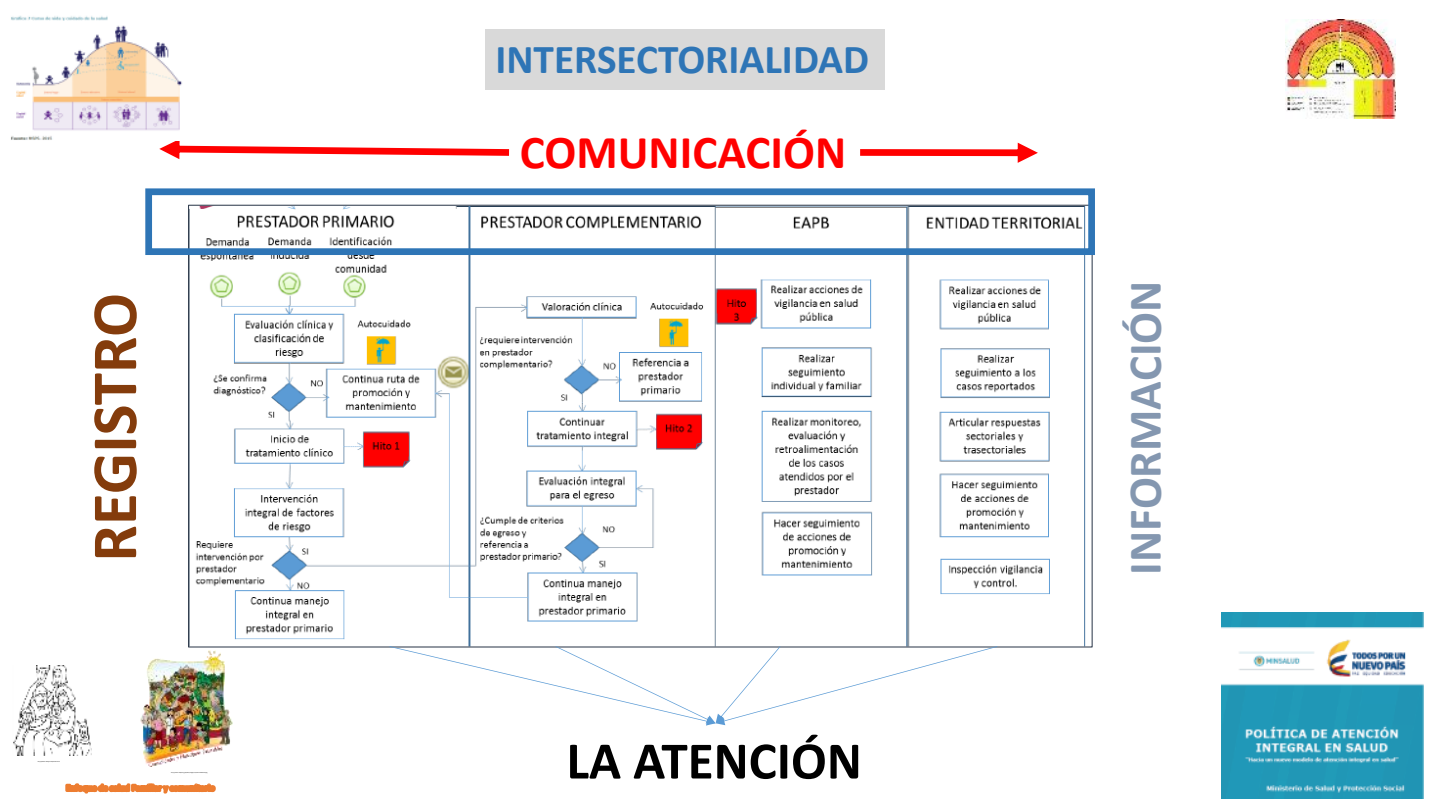

Las rutas deben además de generar la atención de la persona, poner de manifiesto la intersectorialidad, asegurar un registro a través de un sistema de información, en lo posible único y tener una comunicación entre todos los niveles.

\section{La gestión del riesgo}

\section{Implementación de la GIR en salud}

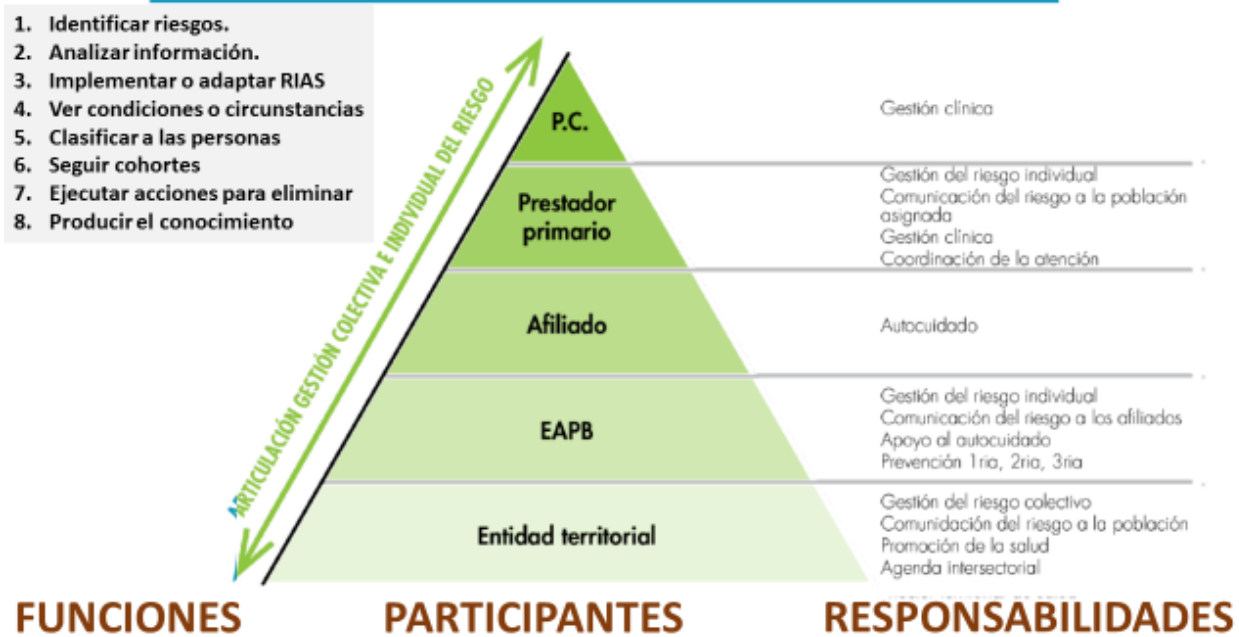

El tercer componente del modelo es la gestión integral del riesgo. En tal sentido y partiendo de la caracterización de la población y articulando a las redes integrales con las rutas, se ponen las tareas de cada nivel. La gráfica pretende mostrar cómo se concibe con sus respectivas correspondencias. 


\section{Delimitación Territorial del MIAS}
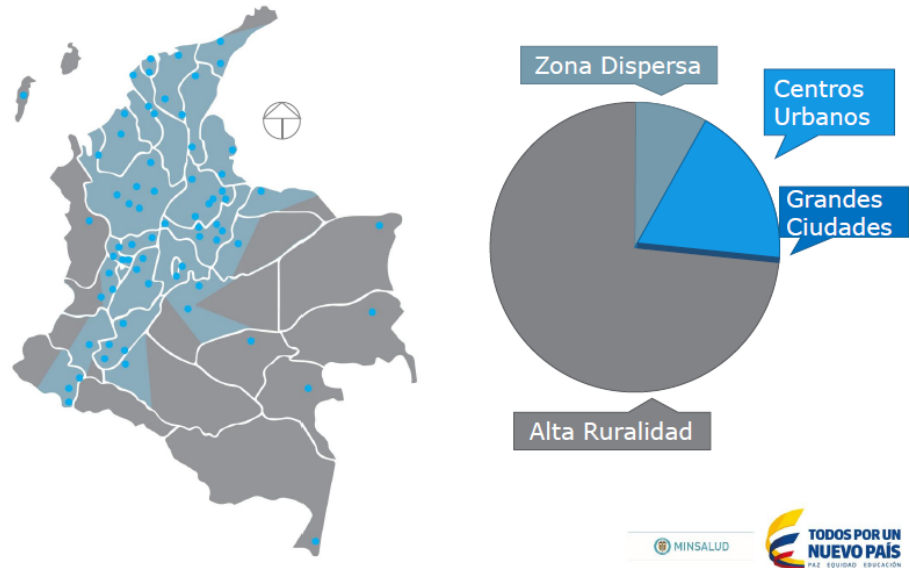

El siguiente componente a tener en cuenta en el modelo lo establecen las características territoriales particulares. En tal sentido, contemplar si se trata de implementar en centros urbanos lo hace diferente de si es en zonas rurales o en lo que se ha denominado zonas dispersas.

\section{Las Redes Integrales de Salud}

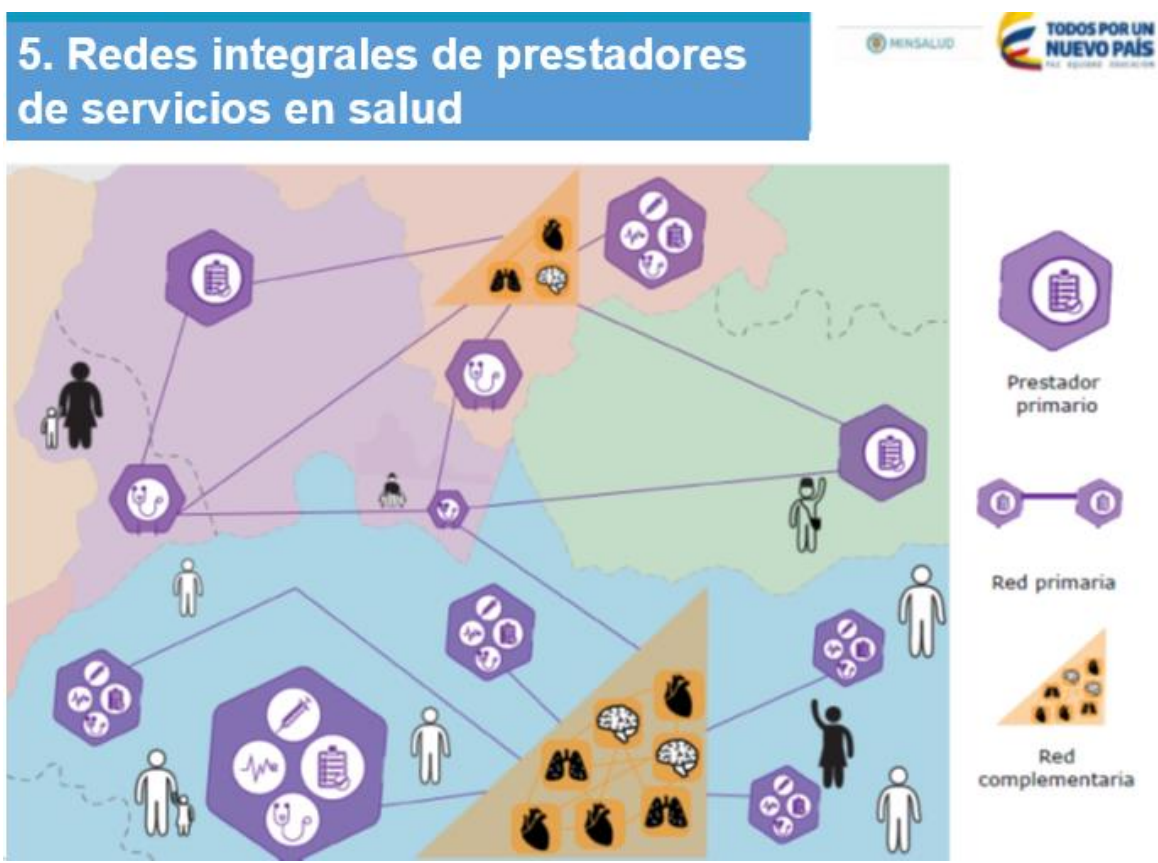

Se entiende como un conjunto de prestadores, unidos para atender a la población, ofreciendo el cubrimiento total de sus necesidades en torno a los servicios de salud. Por supuesto que al interior de ellas se implementarán las rutas integrales de atención. Dicha red debe ser conformada bajo el amparo de las EPS (ahora denominadas EAPB= Empresas Aseguradoras del Plan de Beneficios) y aprobadas por el ente territorial como garante local de los derechos de la población. Las redes deben tener un componente primario que será el responsable de establecer las relaciones con la persona, la familia y la comunidad. 


\section{El prestador primario}

\section{RED Integral Prestador primario}

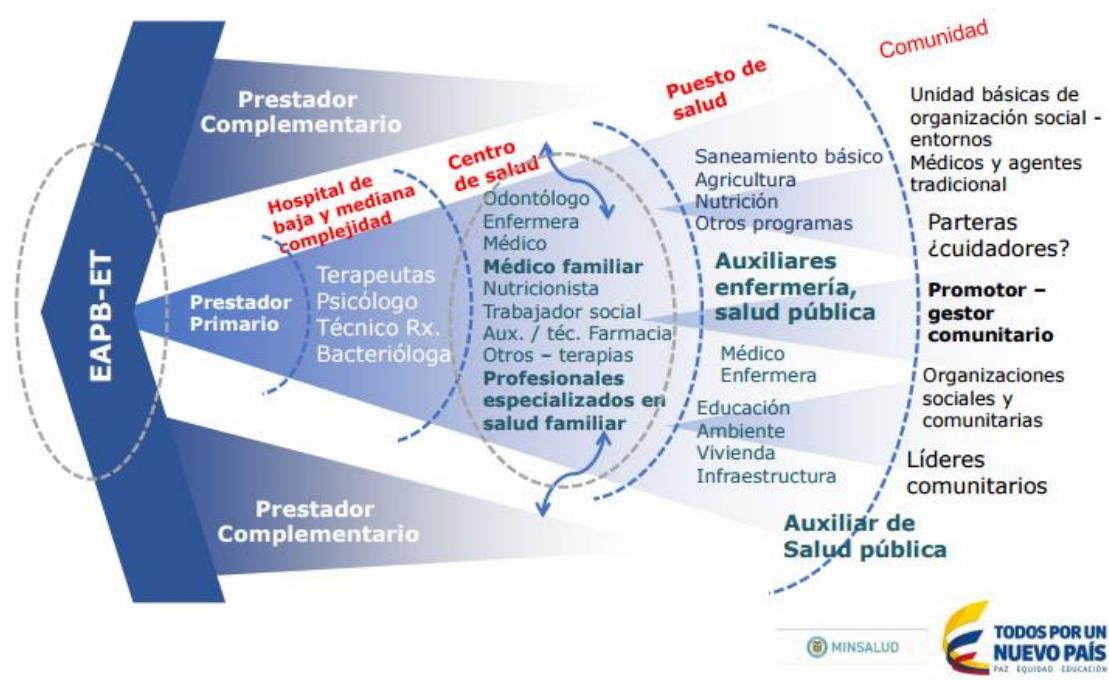

El prestador primario, como primer contacto se convierte en clave para regular y poner a funcionar el sistema de atención. Parte de ese primer sitio donde recurrirá la persona cuando necesita ser atendida y se expande con equipos de penetración en las comunidades, que podrán incluso acudir a los domicilios. La gráfica expresa muy bien todo lo que se espera dentro de la red de los prestadores primarios: se conciben como "capas" de atención, identificadas como comunitarias, de atención básica y de consulta especializada.

Los prestadores complementarios (consulta especializada, hospitales de distinto niveles de complejidad) y la red primaria estarán interconectados, por supuesto que a través de las rutas y entre ellos, por un sistema de referencia y contrarreferencia.

\section{El nuevo papel de las aseguradoras (EPS)}

\section{Redefinición del rol del asegurador}

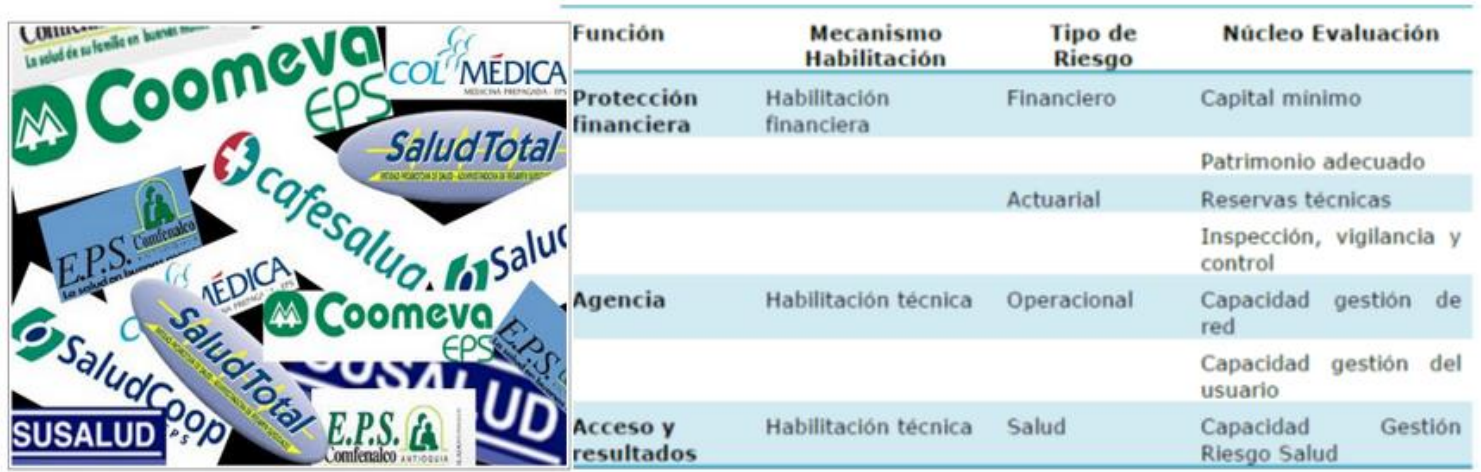

La aseguradora tendrá un nuevo papel. No manejará los dineros sino que velará para que la red que organiza les cumpla a los usuarios. A través de tal confirmación, expedirá la autorización para que la entidad que manejará los recursos le gire a la red. 


\section{Redefinición del sistema de incentivos}

\section{Redefinición del esquema de incentivos}

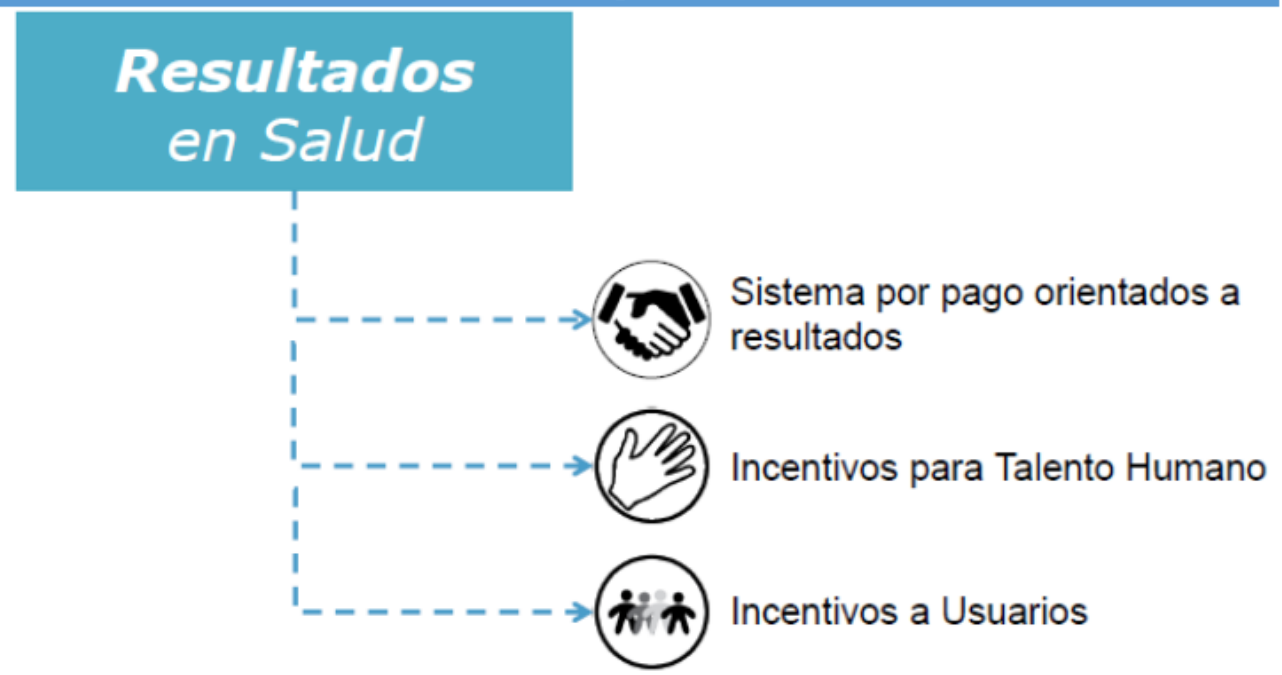

Se debe estimular ante todo el manejo integral de las personas que hagan uso del servicio, siendo la restitución de la salud el principal indicador en torno a las atenciones. Reducir al máximo las autorizaciones (por ello es todo integral) y promover estímulos en los equipos que se comprometen con sus familias, buscando en todo momento una mayor humanización del servicio.

\section{La información}

\section{Requerimientos y procesos del sistema de información}

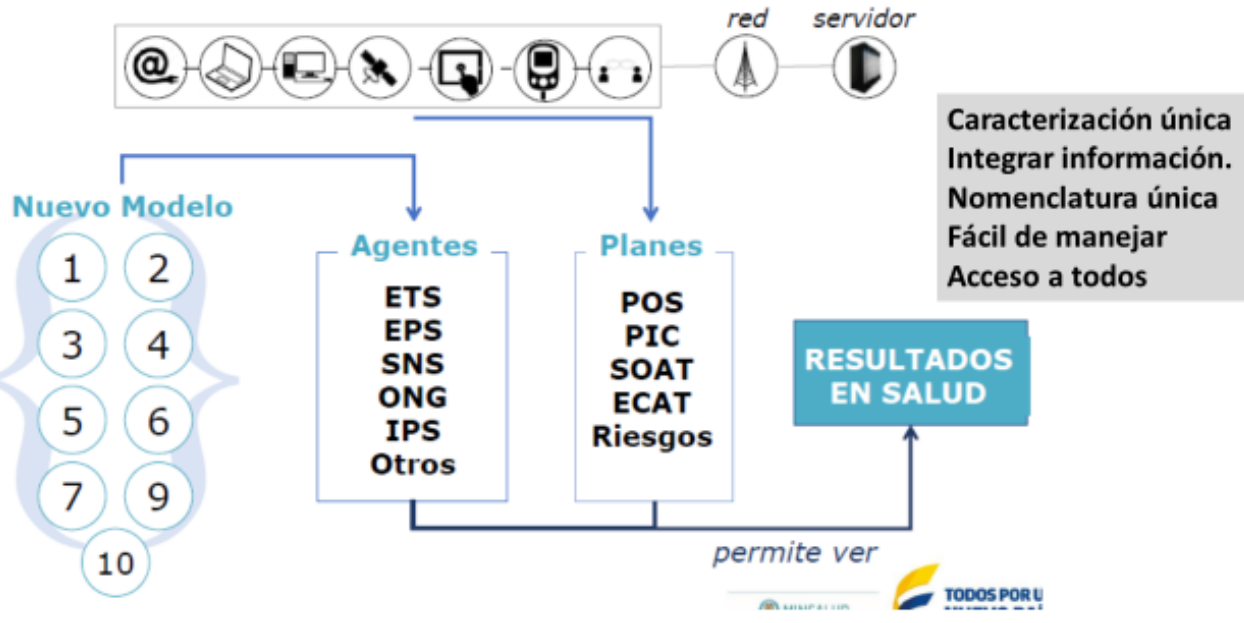

El sistema de información debe estar centrado en la persona, ser y reflejar la integralidad, tener una nomenclatura única, que sea completo... ideal que sea único. 


\section{Fortalecimiento del recurso humano en salud RHS.}

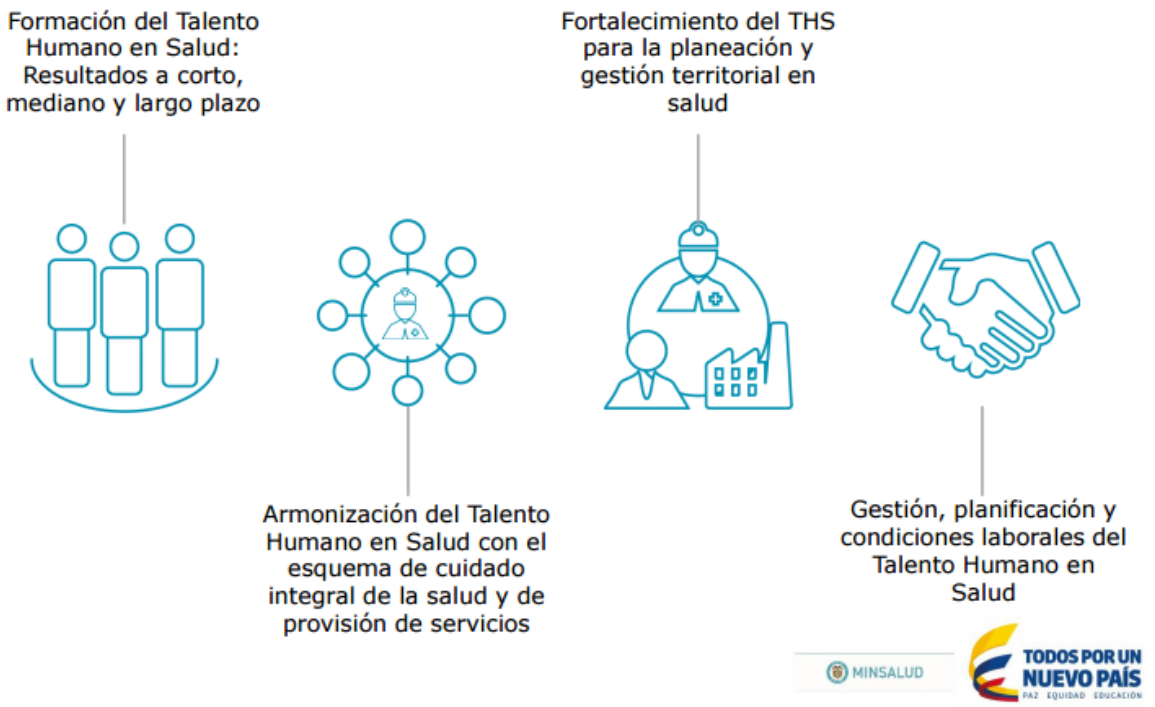

Plantea afianzar particularmente el nivel primario (comunidad), buscando que allí se establezca un fuerte vínculo entre comunidad y prestadores. Fortalecer la capacidad de resolución del prestador primario y lograr penetrar en el corazón de las comunidades son los retos que tienen ante sí estos equipos y que deberán ser debidamente estimulados. Es acá en donde se promueve a los médicos familiares como puentes de integración entre el nivel primario y el complementario.

\section{Fortalecimiento de la investigación, innovación y apropiación del conocimiento}

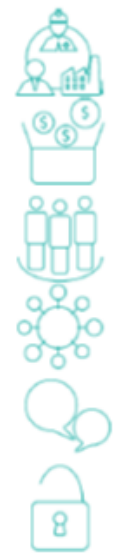

El establecimiento de la rectoría del sistema de salud

Estrategias que garanticen la sostenibilidad financiera del sistema de salud

La gestión eficiente de los recursos humanos en salud

Fortalecimiento de los sistemas de información efectivos y eficientes

Mecanismos efectivos de transferencia de conocimiento en políticas públicas

Investigación en el acceso, utilización y garantía de la calidad de la prestación de servicios de salud

Fortalecimiento de la capacidad de investigación en salud pública

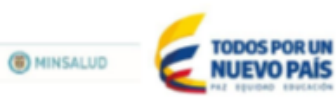

El último aspecto que contempla el documento está esbozado en la imagen anterior. Resaltamos la inclusión de un proceso de investigación permanente. 


\section{Plan de implementación}

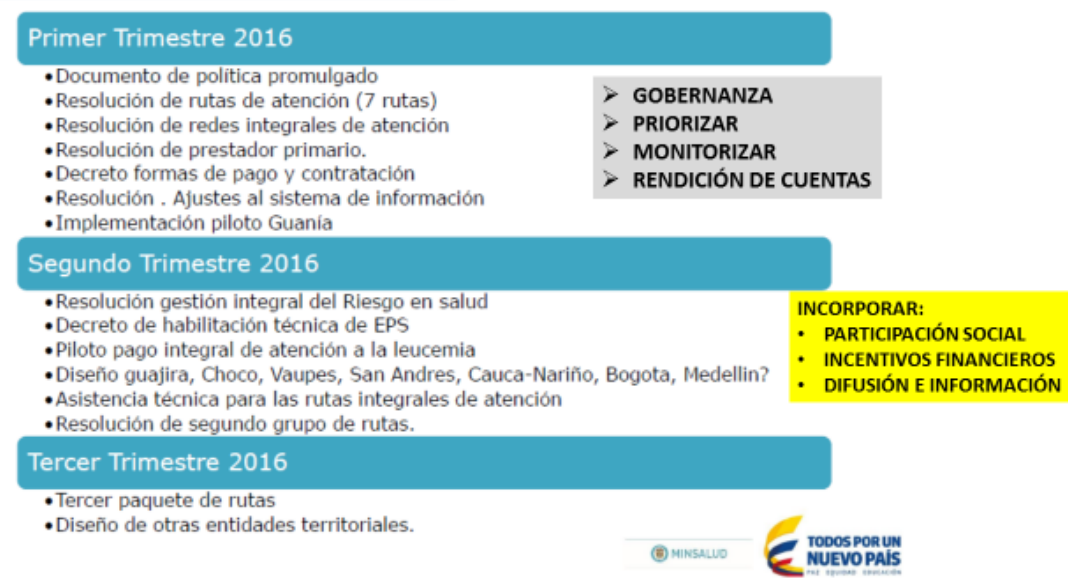

Concluye el documento haciendo unas propuestas en torno a la gradualidad de la implementación y solicita la difusión de la política.

Nuestra intención ha sido exponer el documento de la manera más didáctica posible.

\section{Una opinión}

El Ministerio pretende que la propuesta sea discutida y que se emita el mayor número de opiniones. Con ello se divulga, pero además, se plantean las debilidades y se promueve el debate y las correcciones.

\section{El análisis}

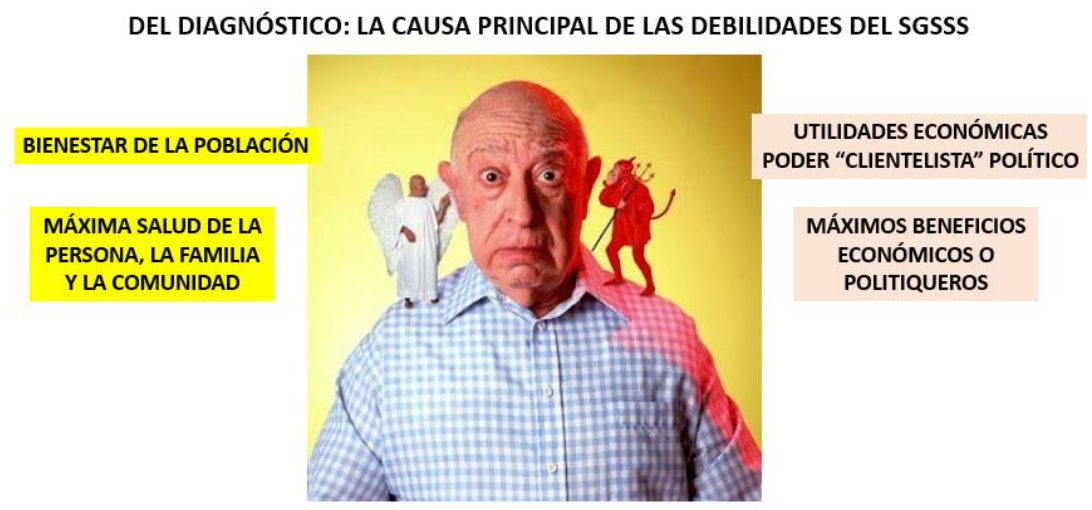

CREER QUE SE PUEDEN UNIR ENTIDADES CON OBJETIVOS DIFERENTES

Nosotros sostenemos que el documento al hacer el diagnóstico de la situación del sistema de seguridad social, desconoció el principal problema, como es creer que entidades con objetivos tan disimiles se pueden unir para servir a la población. Partiendo de los tres entes que plantea esta política que han de coordinar la salud de la población, como son las EPS, el ente territorial y las redes integradas, sostenemos que "unirlas" es un esfuerzo inútil. En concreto sostenemos que el principal problema de la seguridad social se desprende del claro interés que tienen las EPS en torno a "ganar" utilidades desde el punto de vista económico; no es la salud de la población. Esto ha quedado suficientemente evidenciado, al poderse comprobar cómo usando los recursos, una buena cantidad de EPS se dedicaron 
a hacer "negocios", dejando a nivel secundario la salud de la población. Lo propio podemos afirmar del ente territorial, cuyo principal objetivo es la adquisición de poder burocrático y clientelista y no la salud de la población. En tal sentido, tan solo los prestadores tendrían el interés de brindar el mejor servicio a la población.

\section{EL ERROR: CREER QUE SE PUEDEN UNIR ENTIDADES CON OBJETIVOS DIFERENTES}

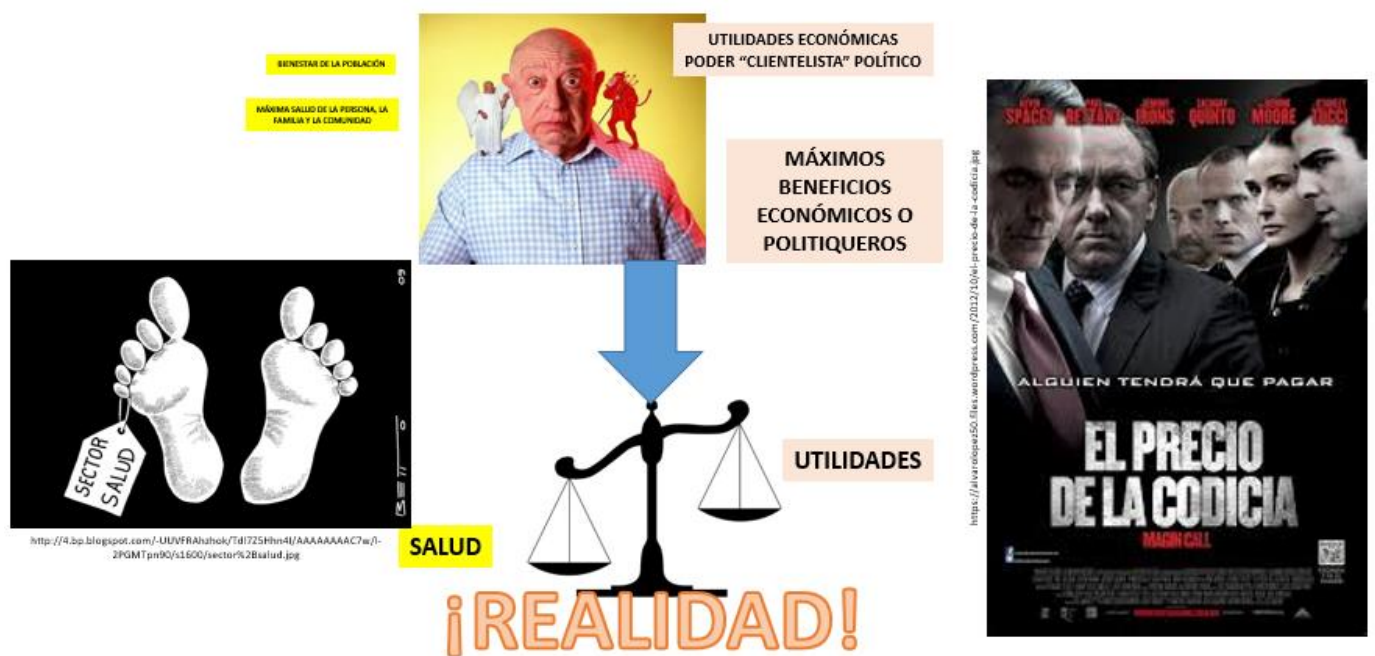

Creemos que existen suficientes ejemplos de la vida real para nuestra afirmación. Ahora bien, como de esos dos sectores el ente territorial debe permanecer por nuestro modelo político, una primera propuesta es eliminar a las EPS del sistema y, en torno al ente territorial, poner a los funcionarios de los mismos bajo el rango de carrera administrativa, con lo cual se anhela que la salud sea dirigida y ejecutada en el ente territorial por un perfil técnico con las ventajas que de allí se pueden desprender.

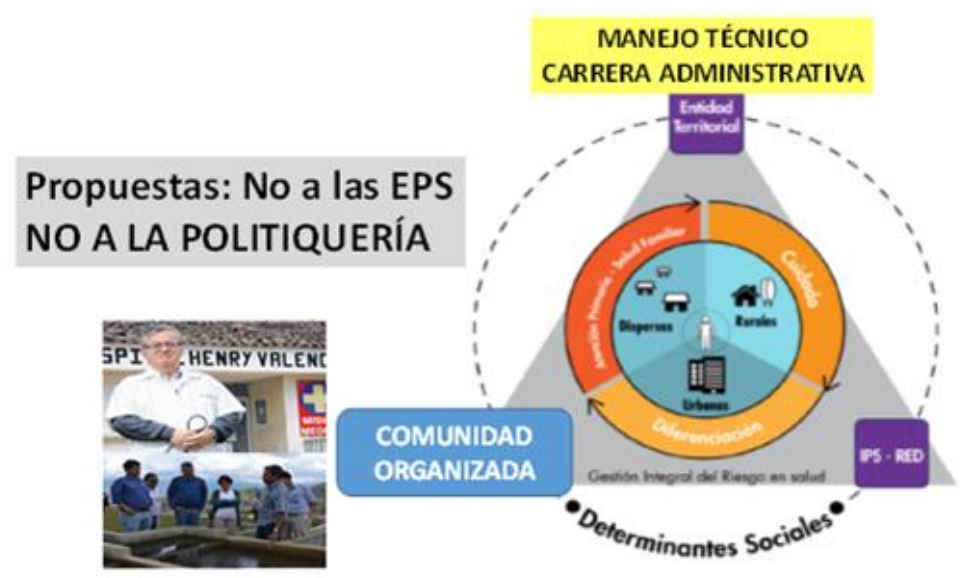

Creemos que ha de ser la comunidad organizada, la que entra a ser esa parte de coordinación del modelo. Experiencias como la desarrollada en Versalles (Valle) ponen de manifiesto lo que la comunidad organizada puede hacer en torno a la salud y otros aspectos. El Misterio precisamente publicó un documento de esta experiencia ( $y$ otras) tildándola como exitosa ${ }^{\ddagger \neq \ddagger}$.

¥¥¥ Análisis y propuesta para el desarrollo de la Atención Primaria, la Promoción de la Salud y el enfoque de determinantes orientados a la reducción de las inequidades, articulado al sistema de salud colombiano. INFORME FINAL. 14 de septiembre de 2012. 


\section{Propuestas: Fortalecer a nivel del cuidado primario}

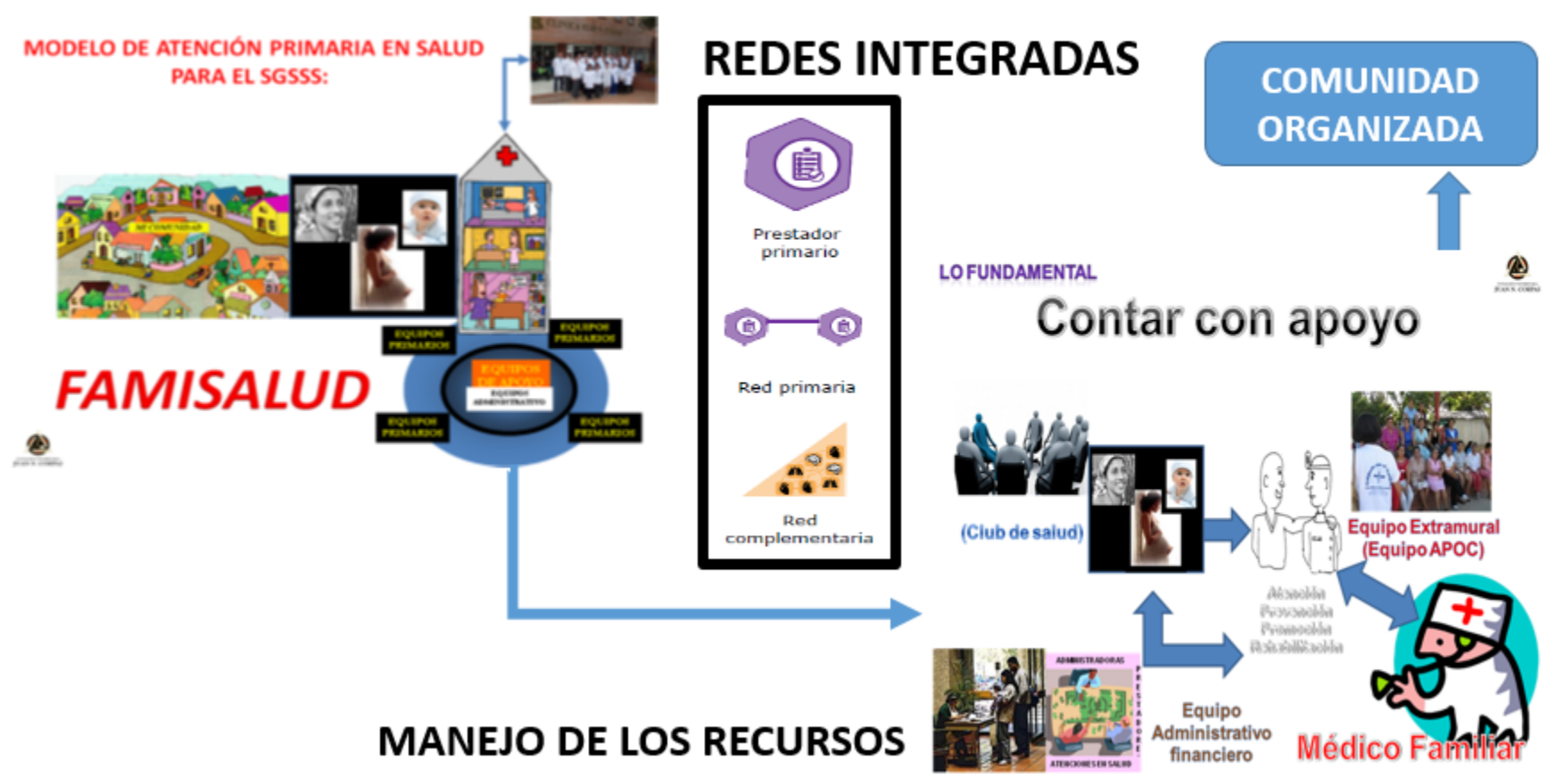

Sin duda, la clave del éxito de la política de integración está en el cuidador primario. Que la población pueda acceder a un centro de salud cerca de su casa, donde sea reconocido y atendido por un equipo comprometido y que cuente con la capacidad para resolver los principales problemas del paciente 0 pueda recibir apoyo cuando lo requiera, por ejemplo por el médico familiar. Tal centro de salud tendrá unos equipos extramurales capaces de penetrar en el barrio y de identificar los procesos comunitarios existentes, lo que contribuirá a organizar y vinculará al centro con el fin de ofrecerle a esa comunidad la mejor atención. Ese equipo de salud será el responsable de caracterizar a la población a su cargo. Desde este centro se construirán las rutas integrales, asumiendo el centro la ruta del mantenimiento de la salud, incluyendo en ella las acciones de salud pública que se puedan ofrecer desde este nivel de atención. Asimismo, y a través de la caracterización, construirá los planes para los grupos de riesgo, dejando bien definidas las rutas en donde incluirá las valoraciones por los especialistas cuando se requieran. Cuando se requiera la hospitalización de algún paciente, el cuidador primario a través de la ruta sabrá remitir al hospital de la red donde pueda recibir la mejor atención (ideal que sea cercano), enviando toda la información pertinente. El cuidador primario (el centro de salud) tendrá un equipo encargado de penetrar el barrio e identificar los riesgos y hacer planes de intervención a través, incluso, de visitas a la vivienda (ofrecerle las acciones de salud pública). Con base en el conocimiento de la zona, promoverá u organizará a la comunidad, la cual se convertirá en participante de los procesos en torno al autocuidado, pero además, en evaluadora de la forma como logra preservar su salud y la forma como es atendida en toda la red. Los miembros de los equipos de salud deben, en lo posible, vivir en esas comunidades. Dado que el compromiso y la continuidad entre prestadores y comunidad es clave, debe trabajar sabiendo que ese es su proyecto de vida laboral, con unas condiciones tales que sienta que está en el mejor sitio. Deberá tener acceso a un programa de educación continuada, que busque, por encima de todo, el bienestar de la población que atiende.

https://www.minsalud.gov.co/Documentos\%20y\%20Publicaciones/An\%C3\%A1lisis\%20y\%20Propuesta\%20para\%20Atenci\%C3\%B3n\%20P rimaria, articulado\%20al\%20sistema\%20de\%20Salud\%20Colombiano.pdf 


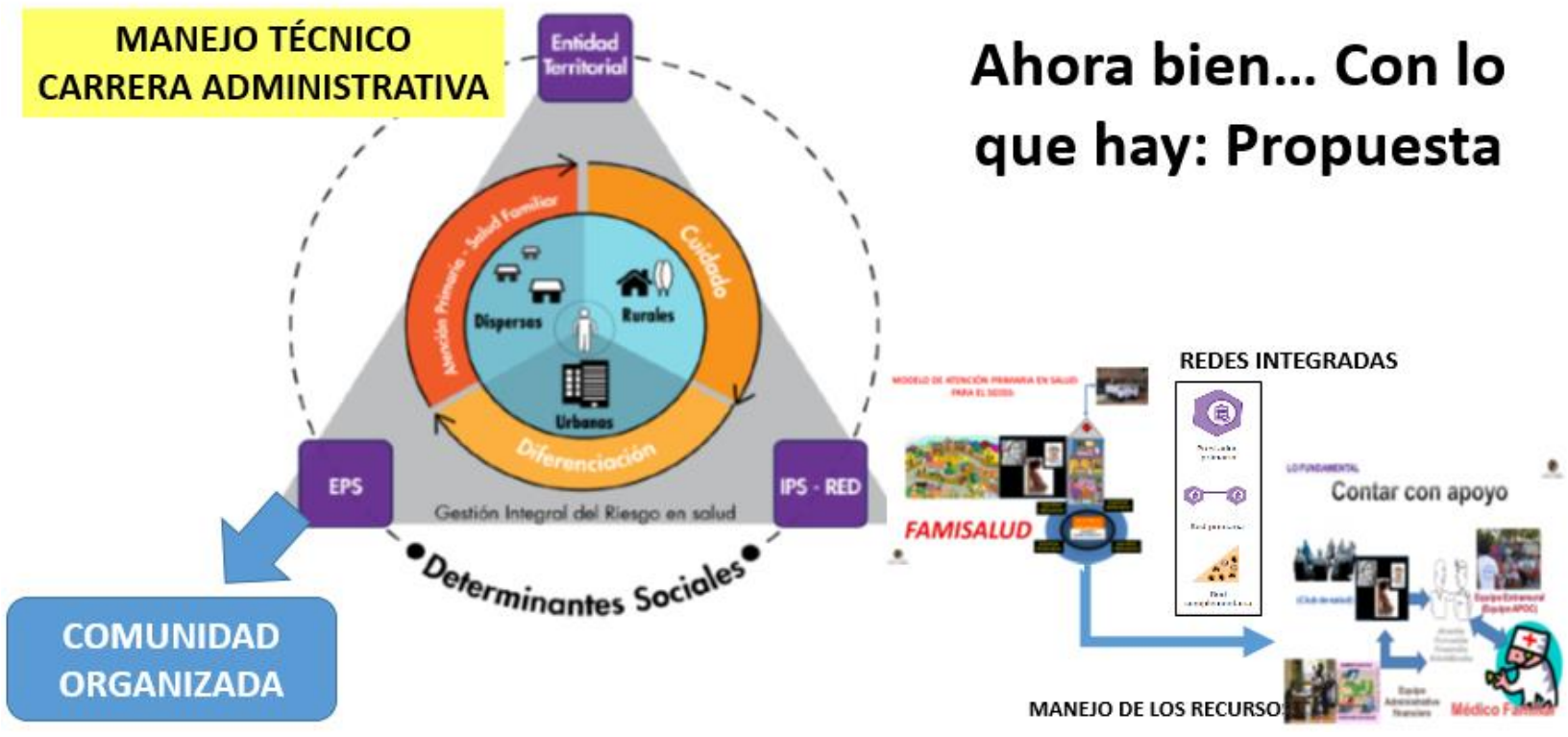

Finalizamos este comentario, proponiendo que, dado que el modelo contempla sostener a las EPS, el papel fundamental de ellas puede ser organizar a la comunidad, asumiendo que de tal organización surgirán los elementos para poder evaluar el modelo.

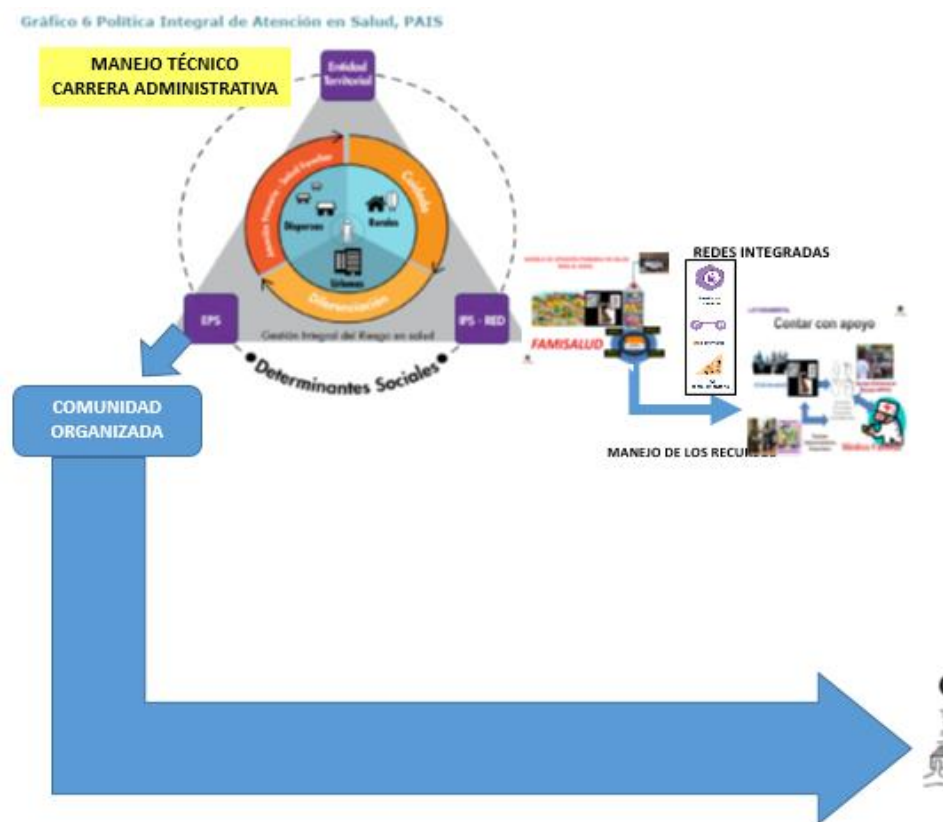

\section{Ahora bien... Con \\ lo que hay: \\ Propuesta}

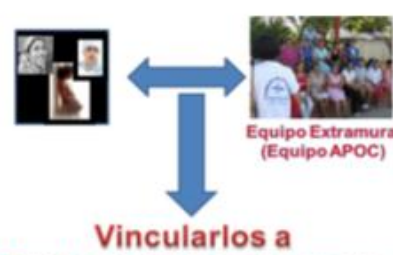

Redes sociales de apoyo

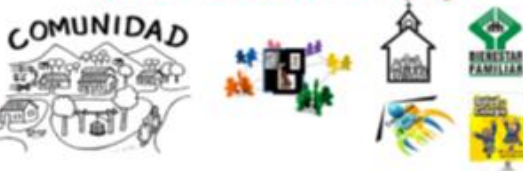

Reiteramos la invitación de nuestros lectores para que analicen la política y, con base en ello, hagan propuestas. La salud en Colombia necesita mejorar. 


\section{OBSERVACIONES SOBRE LA POLÍTICA DE ATENCIÓN INTEGRAL EN SALUD (PAIS)}

Dando respuesta puntual al Ministerio, a continuación y a título por completo personal, respondemos a la solicitud en torno a la Política de Atención Integral en Salud (PAIS).

\section{Por qué no funcionó el modelo establecido por la Ley 100}

En la publicación que hace el Ministerio de Salud y Protección Social, en el documento Política de Atención Integral en Salud, no se hizo el análisis de por qué no funcionó el modelo anterior, aquí queremos destacar algunos hechos que consideramos importantes para no repetir los errores cometidos en la aplicación de la Ley 100 de 1993:

- Se asignaron responsabilidades a tres tipos de entidades, IPS, EPS y Territorio, esperando que se integraran, pero que por tener objetivos distintos no lo lograron (IPS, servicio; EPS, negocio; Territorio, política).

- Cada una de las entidades mencionadas a su vez es fragmentada y, frecuentemente, reglamentaron políticas diferentes, aun internamente en su propia área.

- Ninguna de las cuatro entidades obró lealmente con las otras:

- La función principal de las EPS fue la de contener costos, para obtener mayor ganancia.

- Los municipios convirtieron la salud en un fortín político corrupto.

- Las IPS pecaron por recurrir a la explotación de los funcionarios de la salud.

- El Gobierno Nacional retuvo los dineros, no los giró oportunamente a las entidades a las que debía hacerlo:

* Dio mal ejemplo sosteniendo las EPS más corruptas.

* Se excedió en las reglamentaciones.

* La Superintendencia Nacional de Salud actuó en una forma muy discutible desde varios puntos de vista.

- Los usuarios abusaron del sistema.

- La legislación de otros sectores fue incongruente con la filosofía del sistema. Faltó una política nacional al respecto.

- La sociedad se aprovechó de esto (abogados).

- Exceso de normas que convirtieron al sistema en complejo y engorroso.

\section{Cómo corregir las fallas}

- Integrando el sistema y, como núcleo de la integración, están los prestadores (IPS) formando una comunidad de servicios dirigida por el profesional más capacitado en el campo: el médico.

- Niveles:

- El nivel primario debe tener, a su vez, dos subniveles. Uno de apoyo con las siguientes funciones:

* Elaborar las rutas de atención.

* Gestionar la prestación de los servicios a nivel individual.

* Establecer, gestionar y evaluar la acción con los grupos de riesgo.

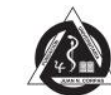


* Manejar contablemente el presupuesto de toda la red de servicios y ser el ordenador del gasto.

* Contratar con el nivel complementario la prestación de los servicios para los niveles superiores.

* Establecer una comunidad de servicios con su red.

* Realizar las consultas de las especialidades básicas definidas para cada territorio, tanto a nivel médico como paramédico y recibir la hospitalización correspondiente a patologías de mediana complejidad.

* Manejar las redes de remisión, contrarremisión e interconsultas.

* Elaborar el plan de salud para el municipio.

* Integrar la promoción, la prevención, la recuperación y la rehabilitación, tanto a nivel individual como colectivo, incorporando todas las actividades de salud pública.

El otro subnivel es el básico, constituido por médicos generales y auxiliares de enfermería como elementos nucleares del equipo de salud, acompañados o no de otros profesionales según el grado de desarrollo de cada Municipio.

El número y composición de los equipos primarios dependerá de las condiciones de desarrollo de cada territorio y del presupuesto total que se maneje.

Este equipo básico trabajará en:

* Hospitales locales.

* Centros de salud.

* Puestos de salud.

Los equipos tendrán como responsabilidades:

* La atención institucional.

* El conocimiento y la programación con las familias que les sean asignadas.

* En conjunto con otros equipos similares de la misma unidad, organizar los programas para grupos, por factores de riesgo.

* Organizar los programas para las instituciones de su área (guarderías, escuelas, sitios de trabajo y ancianatos).

* Realizar una gran vinculación funcional entre los subniveles de apoyo y básico.

Los profesionales de la salud que ejercen privadamente podrán trabajar como adscritos al sistema siempre y cuando cumplan con las normas establecidas por este.

Finalmente queremos agregar que nosotros consideramos que el Modelo de Atención Primaria es un modelo muy bueno para Colombia, debido a que es integral en la prestación de los servicios, tanto individuales como colectivos y, por lo tanto, contempla la promoción, la prevención, la recuperación y la rehabilitación de la salud con gran coordinación intersectorial; se basa en la calidad, contempla todo el proceso de atención e integra a la persona, su familia, la comunidad y sus grupos en un proceso continuo de acuerdo con las necesidades de sus usuarios.

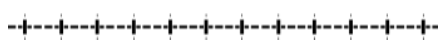

